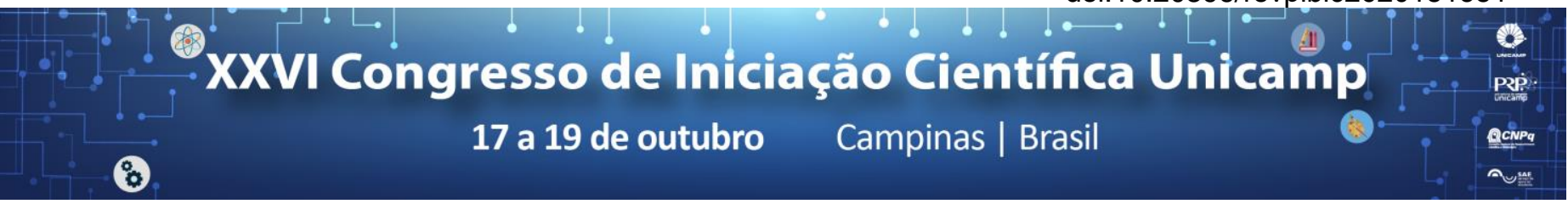

\title{
Study on Microfluidic Paper-based Analytical Device layouts for simultaneous analysis purposes applying colorimetric reactions
}

\section{Wendel Ferreira Santos* e Adriana Vitorino Rossi}

\begin{abstract}
In this project, the adequacy of different layouts for Paper-based Analytical Device ( $\mu$ PAD) for simultaneous analysis in mixtures was evaluated through the use of colorimetric reactions in their reactional zones. Hence, the following parameters of the MPAD were varied: width of the hydrophobic barrier, width and length of the hydrophylic channel, shape and dimensions of the reactional zones, and geometry of the device. The analytical system used in this research was based in comercial tests for domestic quality control of pool water with $\mathrm{pH}$ measure through Phenol Red deprotonation, and free chlorine determination through o-Toluidine oxidation.
\end{abstract}

\section{Key words:}

microfluidic, simultaneous analysis, colorimetric measures

\section{Introduction}

Microfluidics refers to the manipulation of fluids in the scale of micro to nano liters with analytical applications in a series of fields like clinical diagnostics ${ }^{1}$ and environmental monitoring ${ }^{2}$. Several types of reactions can be applied in this kind of system to generate an analytical signal that can be correlated to an analyte concentration. A large range of reactional supports may also be utilized in this context, being the paper-based ones called $\mu$ PAD (Microfluidic Paper-based Analytical Device). In this project, the variation of some parameters in $\mu$ PADs (width of the hydrophobic barrier, width and length of the hydrophilic channel, shape and dimensions of the reactional zones, and geometry of the device) was studied in order to provide adequacy and better performance in simultaneous analysis through the use of colorimetric reactions commonly present in domestic quality control of pool water and visual comparisons with commercial kit results.

\section{Results and Discussion}

The three layout geometries for the $\mu$ PAD that were used in this study were elaborated using the software CorelDraw CorelDRAW X6®, (Image 1). The $\mu$ PAD were produced according to the procedures established by Favero $(2016)^{3}$ e Ferreira $(2016)^{4}$, staying in the oven for an adjusted time of $180 \mathrm{~s}$.
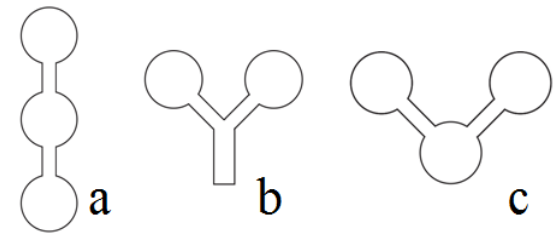

Image 1. $\mu P A D$ layouts with a) linear; b) Y-shaped and c) V-shaped geometry

The colorimetric reactions applied in this research were: the deprotonation of Phenol Red for $\mathrm{pH}$ determination (yellow to pink transition with increasing $\mathrm{pH}$ ), and the oxidation o-Toluidine due to free chlorine (forming a yellow product).

The best geometry found for the simultaneous determination of the two selected analytes was the linear one, which generated a more homogeneous colored spot using a smaller sample volume and with the least risk of cross contamination due to having the biggest distance between the reactional zones. The smallest width for the hydrophobic barrier found was of $0.2 \mathrm{~mm}$; being a circle of $8.25 \mathrm{~mm}$ diameter was the best shape for the reactional zones, with hydrophilic channels of $2.0 \times(4.12$ to 8.25$) \mathrm{mm}$ giving the best results (Image 2). The dynamic range of the analytes detection was established through visual comparisons between the color observed in the paper-based device and the ones present in the commercial kit that correlated to the concentration of each analyte.

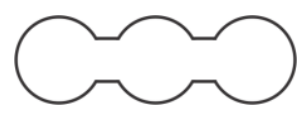

Image 2. Most adequate $\mu$ PAD layout found for simultaneous analysis with linear geometry $8.25 \mathrm{~mm}$ diameter circular reactional zones and $2.0 \times 4.12 \mathrm{~mm}$ hydrophilic channels

\section{Conclusions}

It was determined that the most adequate geometry for the $\mu$ PAD layout for simultaneous analysis was the linear one. The tested concentration ranges for $\mathrm{pH}$ and free chlorine were chosen according to the acceptable values to be present in pool water: for $\mathrm{pH}$ the ideal value was of 7 , and the tested range was from 3 to 10; for free chlorine the ideal range was from 1 to $4 \mathrm{ppm}$, and the tested range was from 1 to $10 \mathrm{ppm}$. An alternative reagent for free chlorine determination was also tested, N-N-diethyl-1 4-phenylenediamine (DPD), which formed a red product when oxidized but its color scale did not match the lowest concentration intended: $10 \mathrm{ppm}$ and thus was not fit for this study.

\section{Acknowledgement}

The sponsoring support from the CNPq is acknowledged. We also thank Acacia Salomão and Arnaldo de Oliveira for all their support.

${ }^{1}$ VELLA S J. et al; Anal. Chem. 84. 2012, 2883-2891.

${ }^{2}$ HOSSAIN S. M. Z.; BRENNAN J. D.; Anal. Chem. 83. 2011 8772-8778.

${ }^{3}$ FÁVERO, A. R.; ROSSI, A. V.; In: XXIV Congresso de Iniciação Científica da Unicamp, 2016. Disponível em: <https://www.prp.unicamp.br/inscricaocongresso/resumos/2016P10310A759303510.pdf>. Acesso em 9 fev. 2018.

4 FERREIRA, P. S.; 2016. Detecção colorimétrica de antocianinas em dispositivo microfluídico a base de papel. Dissertação (Mestrado em Química). Instituto de Química - UNICAMP. 